\title{
The association of oesophagitis with disease in the stomach and duodenum
}

\author{
M. C. BATESON \\ M.D., M.R.C.P.
}

\author{
I. A. D. BOUCHIER \\ M.D., F.R.C.P., F.R.C.P.Ed.
}

Department of Medicine, Ninewells Hospital and Medical School, Dundee

\begin{abstract}
Summary
The records of all upper digestive endoscopies performed in one year in the Clinical Measurement Department of a teaching hospital serving a population of 250000 were reviewed; $25 \%$ of patients had oesophagitis, which was usually associated with other significant findings such as peptic ulcer and gastroduodenal erosions. Only about 1 in 6 patients with oesophagitis had an endoscopically identified hiatus hernia.
\end{abstract}

Oesophagitis was associated with gastric acid hypersecretion in both men and women.

\section{Introduction}

Oesophagitis is usually caused by retrograde reflux of gastroduodenal contents, and various components of the refluxed material have been implicated as causing damage. Previous reports (Williams, Lawrie and Forrest, 1967; Squire, Glick and Benn, 1968; Stol, Murphy and Collis, 1974) involving a small number of selected cases have cast doubt on the role of gastric acid hypersecretion in oesophagitis.

In this study the frequency of oesophagitis is assessed, and its association with other upper gastrointestinal diseases and relationship to gastric acid hypersecretion.

\section{Procedures}

The records of all patients undergoing upper digestive endoscopy during 1979 in the Clinical Measurement Department of Ninewells Hospital were studied. The examination was performed with a variety of forward-viewing instruments by several operators. Oesophagitis was defined as inflammation extending proximally from the gastro-oesophageal junction. Mild oesophagitis was defined as erythema, loss of surface glistening, vascular injection and contact bleeding; moderate oesophagitis as erosions and plaque formation; and severe oesophagitis as discrete ulcers, spontaneous bleeding or associated stricture formation.

Correspondence: Dr M. C. Bateson, Department of Medicine, Ninewells Hospital, Dundee.
All gastric acid secretory studies performed within 6 weeks of a complete endoscopy were analysed. These were performed by specially trained nursing staff in the same department. Pentagastrin $6 \mu \mathrm{g} / \mathrm{kg}$ was given intramuscularly to fasting patients, and the stomach aspirated for $10 \mathrm{~min}$. This collection was discarded, and then the results of aspiration for the next $20 \mathrm{~min}$ were analysed for hydrogen ion content by titration with $0 \cdot 1 \mathrm{~N} \mathrm{NaOH}$ to $\mathrm{pH} 7$ using a $\mathrm{pH}$ meter. The result was multiplied by 3 to give gastric acid output in $\mathrm{mmol} / \mathrm{hr}$.

Results were analysed by Student $t$-test and $\chi^{2}$ test.

\section{Results}

Satisfactory endoscopy was undergone by 1930 patients for a range of digestive symptoms, of which dyspepsia was much the commonest; $381(20 \%)$ had a completely normal examination; 485 patients $(25 \%)$ had endoscopic oesophagitis, of whom 14 had a benign stricture preventing distal examination. The remaining 246 men and 225 women with oesophagitis were studied in detail. Of these 471 patients 276 had at least one additional mucosal or anatomical finding (apart from hiatus hernia). Additional findings were commoner in men with oesophagitis $(166 / 246,67 \%)$ than in women (110/225, 49\%: $P<0.005)$. The findings observed included gastritis and gastric erosions $(23 \%)$, duodenal ulcer $(19 \%)$, duodenitis without ulcer $(15 \%)$, pre-pyloric or pyloric ulcers $(10 \%)$, gastric surgery $(8 \%)$ and gastric ulcer, including one carcinoma (3\%). Many patients had multiple lesions; $21 \%$ of women with oesophagitis but only $12 \%$ of men $(P<0.001)$ had a hiatus hernia (as defined by Wright and Hurwitz, 1979) detected at endoscopy.

The gastric acid output was measured in 67 patients who had normal endoscopic findings and in 127 with oesophagitis (Table 1). Mean gastric acid output was significantly higher in both men and women with oesophagitis. There was a considerable overlap in the ranges, and the gastric acid output did not correlate with the severity of oesophagitis. 
TABLE 1. Pentagastrin-stimulated gastric acid output in oesophagitis ( $\mathrm{mmol} / \mathrm{hr}$ )

\begin{tabular}{lcccccc}
\hline & \multicolumn{4}{c}{ Men } & \multicolumn{2}{c}{ Women } \\
\cline { 2 - 7 } & $n$ & Mean \pm s.e. mean & Range & $n$ & Mean \pm s.e. mean & Range \\
\hline Normal endoscopy & 41 & $29 \cdot 5 \pm 1 \cdot 8$ & $0 \cdot 6-56 \cdot 6$ & $26 \dagger$ & $20 \cdot 3 \pm 2 \cdot 1$ & $0-45 \cdot 6$ \\
Oesophagitis & 77 & $34 \cdot 2 \pm 1 \cdot 8^{*}$ & $1 \cdot 6-84 \cdot 8$ & 50 & $28 \cdot 3 \pm 1.9 * *$ & $1-52 \cdot 2$ \\
\hline
\end{tabular}

* $P<0.05 ; \quad * * P<0.01$. † One patient had achlorhydria.

In patients with oesophagitis but no other endoscopic finding gastric acid output was not significantly different from controls, both for males $(29.7 \pm 3.4 \mathrm{mmol} / \mathrm{hr}, n=15)$ and the females $(24.5 \pm$ $3.3 \mathrm{mmol} / \mathrm{hr}, n=13)$. The gastric hypersecretion in oesophagitis reflected its frequent association with other diseases traditionally accompanied by hypersecretion.

\section{Discussion}

This study showed that oesophagitis is a frequent finding in patients undergoing upper gastrointestinal endoscopy, and is usually associated with other diseases of the stomach and duodenum. A common predisposing factor appears to be a relatively increased gastric acid output. The results are consistent with the concept that patients with gastric acid hypersecretion are prone to oesophagitis as well as duodenal ulcers, pyloric and pre-pyloric ulcers, duodenitis, gastric erosions and gastritis. As with duodenal ulcer, the measurement of gastric acid output is unlikely to contribute to the management of individual patients with oesophagitis. However, manoeuvres to reduce acid secretion without increasing potentially harmful pyloric reflux, such as highly selective vagotomy and cimetidine therapy, are logical treatment for oesophagitis. In contrast to Wright and Hurwitz (1979) these results suggest that hiatus hernia as defined by endoscopy is not usually found in oesophagitis.

There are many different techniques for diagnosing oesophageal disease. Although symptoms can be reproduced by acid perfusion of the oesophagus they do not always correlate with endoscopic findings. The radiological demonstration of hiatus hernia or barium reflux is recognized to be observer-dependent and unreliable. The measurement of lower oesophageal sphincter pressure has not fulfilled its early promise of elucidating the mechanism of oesophagitis. Histology of the oesophagus does not correlate well with either symptoms or endoscopy appearances (Donahue, 1979). Thus endoscopy is probably the most satisfactory method for establishing objective evidence of oesophagitis. The frequency with which oesophagitis is associated with other lesions and the difficulty of accurately assessing the significance of symptoms make endoscopy mandatory in patients suspected of having oeso phageal reflux.

\section{References}

Donahue, P.E. (1979) Gastro-esophageal reflux: some of the mystery remains. Current Surgery, 36, 75.

SQuire, B.H., Glick, S. \& BenN, A. (1968) Maximal acid output and oesophagitis in hiatus hernia. Thorax, 23, 683.

Stol, D.W., MurPhy, G.M. \& Collis, J.L. (1974) Duodenogastric reflux and acid secretion in patients with symptomatic hiatus hernia. Scandinavian Journal of Gastrology, 9, 97.

Williams, C.B., Lawrie, J.H. \& Forrest, A.P.M. (1967) Acid secretion in symptomatic sliding hiatus hernia. Lancet, i, 184.

Wright, R.A. \& Hurwitz, A.L. (1979) Relationship of hiatal hernia to endoscopically proved reflux esophagitis. Digestive Disease and Sciences, 24, 311. 